\title{
Knowing Yourself and Knowing the Others
}

If the corporate decision-makers know the company's resources and capabilities like their own hands, understand customers' habits and their feelings and also the key information of the industry and competitors, then they know their company and industry; if not, they do not know.

\subsection{Introduction}

During war times, assuming that you are assigned to be the commander in the army, your first job is to know how many soldiers you have. What are their strengths? Or what skills do they have? How about their fighting capacity and morale? What kind of and how many weapons and equipment do they own? Secondly, you need to know the situation of your enemies, just as well as you know your own army; thirdly, you may need to learn the battle-related information including terrain, even astronomy and other information. Those facts are very significant to you as a commander, because they are relevant to how you will deploy the troops in an actual battle.

There is a famous saying in military in China, "If you know the enemy and know yourself, you need not fear the result of a hundred battles. If you know yourself but not the enemy, for every victory gained you will also suffer a defeat. If you know neither the enemy nor yourself, you will succumb in every battle". In the case of a

${ }^{1}$ Sun Zi, Attack by Stratagem, Art of War.

(C) The Author(s) 2021 
commercial war, the purpose of "knowing yourself" is to have a clear understanding of the company resources, including what resources, capabilities, strengths (or competitive advantages), and weaknesses (or competitive disadvantages) you have, whether others in the industry are also good at my strengths. If not, are they easy to be imitated and etc.

For business competition, the enemy in the term of "knowing your enemy" is not all the enemies, it refers to the knowing of external environment. It mainly covers three aspects: first is to understand the competitors, such as their number and strength, etc.; second is to know the industry, including the characteristics of the industry, the stage of its development, the competitive situation, and the development trend; third is to understand the industry's consumers, including their consumption motives, habits, and change of habits and so on.

Early in this book, we have talked that if the decision maker does not understand the nature of the internal and external situations of the company, the strategic decision will be very likely not correct. Knowing only the internal situation of the company, but not familiar with that of the external; or understanding only the external situation, but not having the key information inside the company, under both of the two cases, strategic decisions will be biased. Therefore, on the "knowing yourself", "knowing your competitors" and the correct judgment of the information are the assignments that every strategic decision maker must do before making a decision.

If there is a unified approach to estimate whether a decision maker has achieved the "knowing your competitors" and "knowing yourself" for decision making, the situation of strategic decision bias would be improved a lot. But I found it is rather difficult to answer the questions about if a decision maker has accomplished well of the "knowing your competitors" and "knowing yourself".

In terms of "knowing yourself", it may be hard for us to find the unified systematic tools or methods to help us better understand our organization due to the following reasons.

First of all, every firm is like a person. We know that it is difficult to find two people in the world that are exactly the same. Personalities of twins' could be different. Just as a person, each organization is composed of staff of different characters. Its financial situation, management ability, organizational culture, status in the industry and other conditions are different from others on the market. Therefore, it is perhaps not easy to use a unified approach to measure whether the decision maker of the company makes a correct judgment on the question of "Have I had the correct information of my company".

Second, different industries, such as manufacturing, service, IT, finance, and mineral, bear various characteristics. Judgement of resources and capabilities may have different measurement standards for enterprises in different industries. So perhaps we cannot use some unified approaches to weigh the resources and capabilities of enterprises for various industries.

But we know that, we will have no choice but to judge and answer several questions of "knowing yourself" when making real business strategic decisions. Imagine that you want to lead the troops fighting with the enemy for several years 
and you do not know your own troops, features and weapons and ammunition. How dangerous it is!

Although it is difficult to estimate whether the decision maker of the firm has made a correct estimation on several issues of "knowing yourself" with a unified approach, it is believed that there are some very basic methods or aspects that can be adopted to judge the "knowing yourself" issue. Just as each individual is different, we can still use some common indicators to measure a person's health, such as blood pressure, heart rate and etc.

I try to introduce the basic concept and put forward some common aspects as much as possible, allowing readers to determine the issue of "knowing your-self". However, we know that each person's physique is different. Some common indicators for each individual will have a different interpretation, for example, a person usual basal blood pressure is low (such as diastolic blood pressure of 60), and when it reaches 84 , in spite within the normal range, he or she may have felt uncomfortable. Therefore, it should be noted that a decision maker needs to have a fundamental and comprehensive understanding of their own companies, and use industry-specific methods in order to better judge "knowing your-self" issue.

\subsection{Knowing Yourself-To Understand the Company's Resources and Capabilities}

Resources are the tangible and intangible assets a firm uses to choose and implement its strategies (Barney, 2001). Resources are the endowments of various elements owned or controlled by an organization (such as capital, finance, manpower, social relations, etc.). For example, there are 50 students in an MBA class. If we give 1 million US dollars to each person and do not use any other resources, the 1 million is each student's capital and financial resources. Each student himself/herself is a kind human resources and the social network he or she owns is their social resources.

Ability is the capability of organization to utilize resources and achieve the desired purpose (Amit and Schoemaker 1993). Let's say, each student is supposed to repay the capital with interest for onetime after 5 years (assuming 5\% compound interest per year, a total of 1.276 million US dollars after 5 years). Assuming that each student can use the funds without other constraints, what will happen after five years? How to exploit this capital and make it a better return is the embodiment of each student's capability.

For a company, only when it is capable of turning its capabilities into products and services favored by consumers, and the company is able to control the cost well, it then can have good performance and market achievements.

Above, we mentioned some words such as resources, capabilities, products favored by customers and performance achievements. Resources have several types, including financial, human, social and so on. With only resources are not enough for companies to compete successfully in the market, capabilities are 
needed to develop products or services that loved by consumers in the market. And with products your consumers are fond of and the ability of cost control, firms then can have good performance and achievement. Figure 8.1 shows the relationship of these key words.

Let's take a look at the detailed meaning of the contents in Fig. 8.1. Because many of the content itself involve a certain discipline such as financial, accounting, financial management, marketing, etc., here I only briefly introduce these aspects from strategic decision making point of view.

(1) Assets and financial resources

Assets are the "resources" owned by a firm at a moment, including cash on hand, deposits in the bank, equipment and factories, etc., which are the "property" of the enterprise.

The enterprise needs to operate and earn profits from these assets. Enterprises may borrow from banks and other institutions, issue bonds to the public, or occupy the resources of suppliers or employees, which are the "liabilities" of enterprises. Net assets are the part of the assets of an enterprise group that exceeds its liabilities, that is, the net value of all assets minus all liabilities.

Net assets represent the property value of the owner (owner or shareholder) of an enterprise group in the enterprise. It includes equity, provident fund (surplus provident fund, capital provident fund), and undistributed profits and so on.

Whether the financial resources of a company are rich enough or not, we can look at the company's own assets and the earnings generated by the assets. Another it depends on the situation that if the company can take advantage of the use of external financial resources.

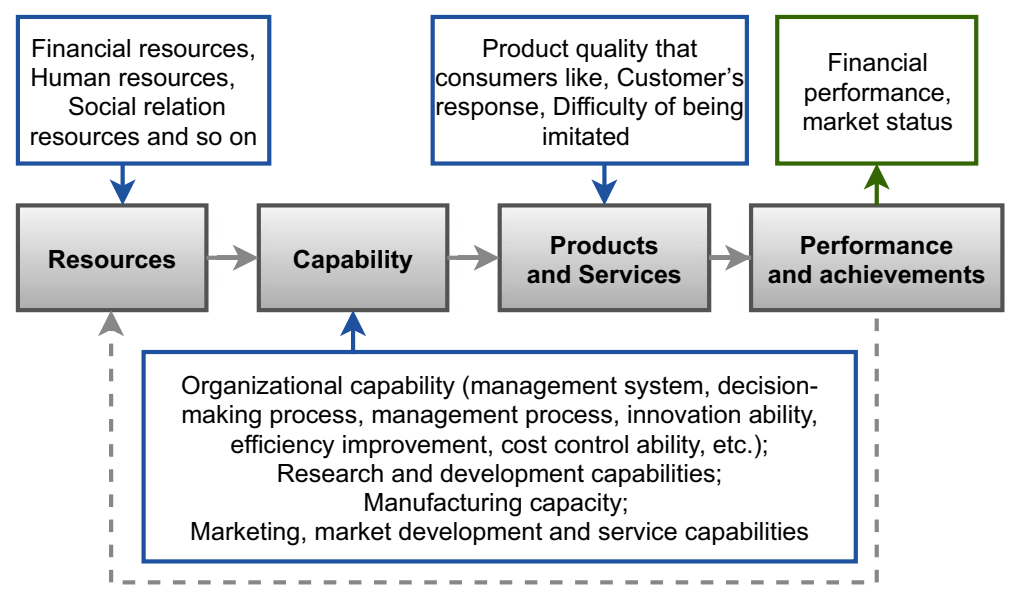

Fig. 8.1 Company Strategic Resources and Capabilities 
Table 8.1 Information of Company Assets and Financial Resources

\begin{tabular}{l|l|l}
\hline Items of Financial resource analysis & Unit & Remarks \\
\hline Total assets & & \\
\hline Total liabilities & & \\
\hline Net assets & & \\
\hline Annual profit & $\%$ & \\
\hline Return on net assets & $\%$ & \\
\hline Average earnings growth of the last 3 or 5 years & & \\
\hline Average profit growth of the last 3 or 5 years & & \\
\hline $\begin{array}{l}\text { Fund raising is easy (1-totally disagree, 2-not quite agree, 3-moderate, } \\
\text { 4-agree, 5-in full agree) }\end{array}$ & &
\end{tabular}

We can use the above Table 8.1 to briefly summarize the information we would like to know.

\section{(2) Human resources}

Human resources refer to the general people or employees in the organization in a certain period of time and their physical strength, the knowledge, the skills that can be employed by the enterprise and contribute to the value creation or the business goal.

One of the tasks of strategy analysis is to understand the basic situation of the company's human resources, such as the total number, gender structure, age structure, educational background structure, category structure, and sub-department structure and so on. Personnel in an organization usually include the following categories: operating personnel, technical personnel, production personnel, and management personnel. The number and allocation of these four types of personnel represent the structure of the internal labor market in the firm.

Large number of employees in an organization do not necessary represent that it has more or better human resources. When there is an excessive number of employees or the skills of the company's staff cannot fulfil the long-term goals, too many staff members can be a redundant. In the strategic transformation period, in general there will be surplus staffs whose capabilities do not fully match well with the company's new goals. Thus in addition to the above basic information, it is necessary to analyze the gap between the existing human resources and the specific human resources required for the achievement of the company's strategic goals. The human resource information and analysis is shown in Table 8.2. 
Table 8.2 Human Resources Information and Analysis

\begin{tabular}{l|l|l}
\hline Items for Human Resource Analysis & Unit & Remarks \\
\hline Total number of employees & Person \\
\hline Gender structure & \\
\hline Age structure & \\
\hline Education structure & \\
\hline Category structure & \\
\hline$\ldots \ldots$ & \\
\hline Characteristics description & \\
\hline Number and structure of personnel requiring training (or redundancy) & \\
\hline $\begin{array}{l}\text { The description of the key personnel required to achieve a strategic goal, } \\
\text { gap analysis }\end{array}$ & \\
\hline
\end{tabular}

\section{(3) Social relation resources}

Relationships are connections or linkages between two or more social "actors" who may be individuals, groups, or larger collectivities (McCall and Simmons 1978). Social relation refers to the relationship and contacts formed by the interaction among individual members or organizations in the society. Managers who have strong social network relationship in an organization, can apply this social relationship working for the interests of the organization (in the case of non-violation of business ethics and law). Therefore, the social relation or network resources of an organization refer to the sum of the social relations that can be applied by the organization and contribute to the organizational goals.

(4) Research and development capabilities

Research and development (R\&D) capability refers to the ability of the organization to develop (or digest introduced technology) and provide the market with the products favored by consumers, based on the knowledge of science and technology, the market demand, the organization's human and material resources. R\&D investment (capital, personnel, etc.) and $R \& D$ management policies have important effect on the R\&D output (quantity and quality). R\&D capability is the result of investment and accumulation of innovative resources.

In general, we can use the number of $R \& D$ personnel and the proportion of expenses accounted for the company's sales to measure its investment and measure its R\&D output through the number of patents that year, the total amount of patents over a period of time, as well as the proportion of new product sales accounted for total sales, as shown in Table 8.3. 
Table 8.3 R\&D Capabilities Analysis

\begin{tabular}{l|l|l}
\hline Items for Research and Development Capacity Analysis & Unit & Remarks \\
\hline Annual R\&D spending & & \\
\hline Total number of R\&D personnel & & \\
\hline Number of key R\&D personnel & Item & \\
\hline Number of patents this year & Item & \\
\hline The number of key patents this year & $\%$ & \\
\hline The number of patents increased over the past three years & $\%$ & \\
\hline Average ratio of new product revenue to total in recent 3 years & \\
\hline $\begin{array}{l}\text { The company has a sound management system of R\&D and innovation } \\
\text { (1-totally disagree, 2-not quite agree, 3-moderate, 4-agree, 5-in full agree) }\end{array}$ & &
\end{tabular}

(5) Manufacturing and production capacity

Manufacturing capacity refers that an enterprise can convert a design drawing to a finished product that meets the requirements. Production capacity refers that in a certain period of time enterprises use fixed assets and other resources to produce the maximum number of qualified productions, or the number of raw materials handled by qualified processing. Production capacity reflects the scale of enterprise production.

As the production needs the site and equipment, a company will locate the production and manufacturing sites away from the city for a little distance, such as Kunshan, near Shanghai China, is a place where manufacturing is concentrated. According to the Smile Curve, the added value of manufacturing is lower than the design in the front end of its value chain, and is lower than the sales and service of the back end. Therefore, some companies specializing in brand, product designing and sales, such as Apple (mobile phone), Nike (sports shoes) and other companies, will outsource the production and manufacturing to the market manufacturers. However, for some complex product industries (such as cars, boats, aircraft), manufacturing capacity reflects not only the company's production scale, also the embodiment of technical capacity applications, which is a high degree of organization and coordination capacity. Table 8.4 shows the manufacturing and production capacity of the company.

(6) Marketing and sales capability

Marketing capability refers to the ability of an organization to create, communicate, disseminate, and exchange products, processes, and systems that create value for customers, partners, and society. Sales ability is the most direct expression of business marketing ability, so in terms of the output, the increase of company sales volume in a certain time is the embodiment of marketing ability. 
Table 8.4 Company Manufacturing and Production Capacity Analysis Table

\begin{tabular}{l|l|l}
\hline Items for Production and Manufacturing Capacity Analysis & Unit & Remarks \\
\hline Design production & & \\
\hline Annual production & $\%$ & \\
\hline Percentage of qualified products & & \\
\hline Average annual growth (or decline) in recent 3-5 years & & \\
\hline Number of production personnel & $\%$ & \\
\hline Proportion of medium or high-level technical workers in production & &
\end{tabular}

The results of the enterprise sales are associated with its numbers and quality of available channels, and its investment funds in marketing and personnel, but also with the enterprise marketing practices. Therefore, a company's marketing and sales ability, not only reflects in its size (sales volume, the number of channels, funds and personnel, etc.), but also in its management capacity, such as sales staff per capita sales volume, unit channel funds sales, sales increase in the year, and in some later years which is result from the company marketing investment in this year. All these reflect the company's marketing and sales staff and organizational skills, as shown in Table 8.5.

\section{(7) Organizational capability}

There is not a basically agreed upon interpretation about what is organization capability of a firm in the literature. Here, I briefly introduce my understanding of this concept.

Let's take a look at the changes in China's economy before and after the reform and opening up policy. Before the reform and opening up, China was implementing the planned economy, which was a systematic system. Things such as where to purchase raw materials, what and how many to produce and who to sale, were not decided by the market, but unified national arrangements. Enterprises didn't have

Table 8.5 Company Marketing and Sales Ability Analysis Table

\begin{tabular}{l|l|l}
\hline Items for Marketing Ability Analysis & Unit & Remarks \\
\hline Annual sales in volume & & \\
\hline Annual sales & $\%$ & \\
\hline Sales volume this year compared with last year & $\%$ & \\
\hline Nearly 3-5 years sales volume average growth (or decline) & & \\
\hline Number of marketing and sales staff & \\
\hline Marketing and sales expenses & \\
\hline $\begin{array}{l}\text { The company has a sound marketing and sales system and policy } \\
((1-\text { totally disagree, 2-not quite agree, 3-moderate, 4-agree, 5-in full } \\
\text { agree) }\end{array}$ & \\
\hline
\end{tabular}


the autonomy in the production and operation. In 1979, per capita GDP was only 419.8 yuan (around US $\$ 70$ annually). In the early 1980s, China implemented reform and opening up, and the government gradually changed the model of the planned economy into market economy with Chinese characteristics. Within 30 years, per capita GDP increased significantly to 46,600 yuan in 2014 , compared with 1979 by 100 times. Such a big change attributes to institutional policy changes.

From a strategic point of view, the most important side of a company's management system is to ensure decisions are based on the correct understandings of the origin of things and are correct. The decisions could be concerning the motivation of employees, capital investment, new product development and etc. A good decision-making process will ensure that major decisions not be wrong. Companies who are mature in management system and capabilities normally have decision procedures and polies which are beneficial to expected decision outcomes.

There are diverse employees in a company. The extent to which they will transform their ability to achieve business goals depends heavily on the firm's management system and policies related to employees' interests. A good management system will be conducive to employee motivation and initiatives.

An organizational capability of a firm lies in its management system (personnel system, salary system, incentive system, capital management system, etc.), important work processes and decision-making processes (decision-making process of major capital to use and major project, etc.), which is the ability needed for its long-standing goal.

Organizational ability is a product of an organizational structure, process and control system (Hill 2007). A company with strong organizational ability could adapt to the needs of market changes, innovate business models or products, effectively control cost, and have higher efficiency than competitors. Table 8.6 shows the organizational capability analysis.

Table 8.6 Organizational Ability Analysis Table

\begin{tabular}{l|l}
\hline Items for Organizational Ability Analysis Project & Analysis \\
\hline $\begin{array}{l}\text { The company's cost budget, cost control system and process (poor, in need of } \\
\text { improvement, mediocre, good, perfect) }\end{array}$ & \\
\hline $\begin{array}{l}\text { The company can pay close attention to market changes and take response } \\
\text { measures (cannot, sometimes can, mediocre, good, perfect) }\end{array}$ & \\
\hline $\begin{array}{l}\text { The company has a sound incentive system for its employees (no, somewhat, } \\
\text { mediocre, good, perfect) }\end{array}$ & \\
\hline $\begin{array}{l}\text { The company has a sound decision-making process on the major issues (no, } \\
\text { somewhat, mediocre, good, perfect) }\end{array}$ & \\
\hline $\begin{array}{l}\text { The company has a sound work flow that is conducive to the completion and } \\
\text { improvement of the main works (no, somewhat, mediocre, good, perfect) }\end{array}$ &
\end{tabular}


(8) Product (services) quality and customer response

Product (or service) is the way that a business transforms their own efforts into the value of consumers, which is the basis for enterprises to create profits. Hill and Jones (2007: p. 89) argue that a product is a combination of attributes that include utility, reliability, shape, characteristics, persistence, style, and design, etc.. If consumers consider that the attributes of a product are better than other competitors', this product will provide consumers greater value.

Different consumer groups have different understanding and preferences for product attributes. For example, the style, color and heel height of shoes have higher value for young girls than for older women. Services also have the quality concept, for example there are several companies selling second-hand cars. Which one will consumers choose? As a customer, you want the situation of the used car introduced by the second-hand car dealer to be real, the price reasonable, and you also want to have more selective choices, and those are quality in the eyes of customers for second-hand car service business.

With the continuous development of science and technology, consumer demand for product attributes is also getting higher and higher. For example, as for mobile phone products, in the early 90s palm phone is a symbol of status in China, and now almost everyone have the palm laptop. Its technical properties, design, color and other attributes have experienced development of several generations. An enterprise which can constantly improve the product attributes in the changing market, and develop new properties and continue to bring new value to customers, will be favored by the market.

Customer response is that either the customers choose the company's products (services) or the company's products (services) have some problems; then the company either provides the required products (services) or deals with the problem. Response time is an important indicator of a company's response ability, and long response time will increase customer's dissatisfaction with the company's services. In customized products and services, good customer response requires companies to have good management capabilities. In today's society of information and Internet, customer response time has become shorter, even for customized products and services, customers also hope to enjoy the value of the purchase in the shortest possible time.

(9) Imitation issue

When a company owns the products favored by customers, someone in the market will imitate. If all the attributes of the product can easily be imitated, the company only has temporary product advantages. Companies normally do not hope that their products are easily imitated.

In general, some properties of a product are easy to be imitated, such as appearance, color and so on. But to imitate all the properties and their combination of a good product, imitators need to have a certain level of capability. For example, 
Leonardo da Vinci's portrait, Mona Lisa, has countless imitators, and some get the mouth, and some get the eyes, but few people can imitate the whole picture to the level of the original painting of Da Vinci. Therefore, if a product has many attributes and is difficult to integrate them, then imitation will become hard.

I have asked students several times in my strategic management classes, the students using Apple computers, why would they buy Apple computer? What did it attract you? The answer is not about Apple's computer system, but an elegant and beautiful feeling. Elegant and beautiful is the concept of art level, it is difficult to be imitated. Based on the basic functions of the product, the appearance of the product, design, unique color, fine workmanship and so on have to be ultimate in order to deliver elegance and beauty feeling. Elegant and beautiful is the integrated effect of the embodiment of all attributes in the product.

In general, as long as a company has enough capital funds, it can gain the abilities at functional levels from market by hiring peoples who have experiences in marketing, R\&D, etc. Imitation seems inevitable, but Collins (2010) argues that imitation has barriers.

One barrier is the special geographical location. Particular geographical position gives a company a competitive advantage. We all know that the Persian Gulf region contains the world's richest oil resources. $70 \%$ over-100 million- tons oil fields on the earth are in this area. Natural gas remaining recoverable reserves also account for $26 \%$ of the world's total reserves. The land oil resources in the surrounding countries such as Kuwait, Iraq, Saudi Arabia, Qatar, Bahrain and Iran are abundant as well. Such as Kuwait, which has less than 1 million people, and oil reserves and production are similar to China, with population of 1.3 billion. Other countries cannot imitate their special geographical location.

The second barrier of imitation is the fact that the present ability is based on the accumulation of past learning and experience. For example, a very experienced old Chinese medicine doctor, he (she) has superb medical technology based on the accumulation of the past few decades. This experience is difficult to be imitated in a short time by others. An enterprise's management capability, if it is based on a solid system which is formed through continuous improvement, and is able to adapt to the changing needs of the market, other companies will be difficult to imitate, because a company's management system, decision-making system, processes are all related to "people", and the interaction between people. These systems, processes are often the representative of the corporate value, representative characteristics of employees, but also the company's history and status.

The third barrier of imitation is inability to know. That is to say, we do not know what it is the real reason that a company has a good performance. If you do not even know the reasons, we cannot know how to imitate.

The fourth barrier of imitation is cost. If imitation has to pay the expensive costs, some companies won't be able to get it due to the lack of funds. Table 8.7 shows the quality and imitability analysis of the company's products (services). 
Table 8.7 Company Product (Service) Quality and Imitability Analysis Table

\begin{tabular}{l|l}
\hline Items for Product and Imitability Analysis & Analysis \\
\hline $\begin{array}{l}\text { The company's products compared to competitors are better in quality, design, } \\
\text { utility and other aspects (completely disagree, not agree, basically agree, agree, }\end{array}$ & \\
fully agree) & \\
\hline $\begin{array}{l}\text { The company in the customer response, does better than the competitors } \\
\text { (completely disagree, not agree, basically agree, agree, fully agree) }\end{array}$ & \\
\hline $\begin{array}{l}\text { The company's products are not easy to be imitated by competitors (completely } \\
\text { disagree, not agree, basically agree, agree, fully agree) }\end{array}$ & \\
\hline $\begin{array}{l}\text { The company's competent management systems are not easy to be imitated by } \\
\text { competitors (completely disagree, not agree, basically agree, agree, fully agree) }\end{array}$ &
\end{tabular}

\section{Company performance and achievements}

Company performance and achievements are the outcomes of the whole company over the years, a comprehensive embodiment of the company's research and development capabilities, manufacturing capacity, sales capabilities, i.e. the company's core competitiveness.

Sales revenue (usually referring main business) is not only the embodiment of the company scale, but also the comprehensive demonstration of the value of the product or service and the company's sales capabilities. Profits (profitability level), asset yield and other performance indicators reflect the company processes, cost control ability, and decision-making capability. The trend of those indicators reflects the company's performance over a period of time. For a prosperous company, its sales revenue and profit should be on the rise, either fast or slowly. And a downhill company, due to its weak organizational capability, or decision-making mistakes, the performance would go downward.

We can use the following table to summarize the overall company performance and achievements over a period of time. ${ }^{2}$ (Table 8.8).

We have introduced some concepts of corporate resources and capabilities. As the company's top managers, strategic decision makers need a clear understanding of the company's property situation, including questions of how much assets do I have? How much the fixed asset is? How much the debt is? How much the annual revenue is generated by the asset? When the company is in the need of large amount of capital, can I raise money from the market? How about the channels, difficulty and cost of fund-raising?

Decision makers also need a basic understanding of the human resources including the number, age, structure, and personnel of the company. Like the commanders in the war, you need a very clear understanding of your troop characteristics. In addition, you need to have a clear insights of the company's R\&D

\footnotetext{
${ }^{2}$ Corporate innovation and market achievements are not included in this table due to previous mention.
} 
Table 8.8 Company Performance and Achievement Analysis Table

\begin{tabular}{l|l}
\hline Company Performance and Achievement Analysis Project & Analysis \\
\hline The company's average growth rate of sales revenue in past three years & \\
\hline The company's average profit growth rate in past 3 years & \\
\hline $\begin{array}{l}\text { Compared with the competitors, the company's income, profit performance is } \\
\text { satisfactory in nearly } 3 \text { years (completely disagree, not agree, basically agree, } \\
\text { agree, fully agree) }\end{array}$ & \\
$\begin{array}{l}\text { The company's market position is satisfactory in nearly } 3 \text { years (completely } \\
\text { disagree, not agree, basically agree, agree, fully agree) }\end{array}$ &
\end{tabular}

Industry Special Information:

investment, R\&D personnel, R\&D output (number of patents, new products), sales volume, sales revenue and growth.

It should be noted that each industry has its own special indicators. Decision makers need to know well of the information showing industry characteristics.

Through the above information, decision makers can basically be aware of their company's own strengths and weaknesses. But does the company have some hidden special abilities? For example, you have an army, you can understand the size, personnel structure, supply situation, weapons and ammunition equipment, logistics, etc. through data information, but the morale of the troops and unique combat capability is difficult to know from the figures, which needs troop leaders to investigate through routine training and combat situation. Company situation will be the same as a troop. Besides decision makers will have a better understanding of the company if they can make comparative analysis with main competitors in the industry for above information.

If a company has more financial resources and better human resources than its main competitors, the company owns the financial and human resource advantage. If a company has better capabilities in $\mathrm{R} \& \mathrm{D}$, manufacturing, marketing, the company possesses these competitive advantages of functional level. If a company has the organizational capabilities that are more consistent with the development of the market and the long-term goals of the company, the company has an organizational advantage. If a company's products are favored by consumers, and bring the company the better benefit than the competitors, the company has a competitive advantage. If a company has the resources and the ability that others cannot imitate, we can say that the company has a sustainable competitive advantage.

We have introduced some information that decision-makers need to be conscious of. "Knowing the other" is mainly about understanding the industry, consumers and competitors from the perspective of the strategic development. Next we look at "knowing the other". 


\subsection{Knowing the Other-To Understand the company's External and Industry Environment}

In commercial competition, "knowing the other" refers to the knowing of the others. Knowing the others not only include the understanding of competitors, but also the development trend of the industry, the behavior of company's main customers, the main suppliers, as well as regional politics, economic, legal and other environmental impact on the industry (including the impact on the industry manufacturers, on the industry's consumers, etc.).

Different from "knowing yourselves", "knowing the others" is more about analysis, judgment and prediction due to the lack of full information of the "others". Here we are going to explore the evolution of an industry trends and changes from three aspects: the industry life cycle, consumers and competitors. From the evolution, we will be able to examine which stage is in now of an industry and be able to predict where it will be in near future.

\section{(1) Industry development life cycle}

Industry life cycle refers to the process that the industry products emerge in and retreat from social and economic activities. The life cycle of the industry generally includes four development stages (Vernon and Wells 1966; Vernon 1979), which are incubation or introduction period, growth, maturity and recession periods.

The introduction stage is when products or services just come out; the design is not mature, the quality is not stable and technology has uncertainties. On the other hand, the market is generally more interested in new things, so that demand grows faster. Enterprise craves to developing new products, and occupying the market. The main barrier to business entry is the technology. For example, the mobile phone industry, the first mobile phone in the world was born in the Motorola laboratory in Manhattan, New York in April 3, 1973. The emergence of mobile phones brought the beginning of a new era. In 1987, palm phone (commonly known as mobile phone) went into China, and it became an important tool for people in communication and social interaction. At that time the product was heavy, functionless except calling, and voice quality is not clear and stable at all, and its battery can only support $30 \mathrm{~min}$ of talking. But even so, market price of the palm phone was more than 10,000 RMB while GDP per capita was only about 5000 RMB per year. Therefore, it was indeed a symbol of identity.

For the service industry, it is important for companies in the industry to find a good profit model in the embryonic period, once the profit model is accepted by the market, the industry will enter the growth period.

In the growth period, the industry's product technology tends to be stable; the market demand is greatly increasing. There is an increase of industry entrants. As the number of competitors keep increasing, industry capacity enlarges. Industry competition grows intense, and industry manufacturers will develop new products, 
and product quality at this stage is constantly improving, but owe to increased competition, product prices will decline in the mid-growth period.

Some service industries require small investment for its projects. Once the profit model is accepted by the market in the embryonic period, it can soon be imitated by the potential entrants in the market. Therefore, the number of competitors in the industry will increase. In the medium-term growth period, the competition will intensify, which will lead to a decline in prices, or to further improved quality of service.

In the maturity stage, the product is technically mature, but the demand is no longer rising and sometimes even meet with a slight decline. Industry profitability is declining. New products and the development of new uses will be more difficult, and small manufacturers began to withdraw from the industry.

In the maturity period of the service industry, on the one hand, there are a large number of competitors; on the other hand, demand reduces (such as economic downturn, income reduction), resulting in reduced industry demand, some small enterprises began to withdraw from the market.

In the recession or decline period, there is overcapacity in the industry, and the market demand for the products has dropped significantly. Due to the decreased demand, product variety and competitors decrease.

In the recession period, service industry demand dropped significantly, the original industry enterprises will withdraw one after another.

In most industries, when a category of products are in a recession, there will emerge replacement products, and drive a new round of development in the industry. Service industry will get better quality, or cheaper alternative services (Fig. 8.2).

Understanding of development stages in the industry is important for strategy formulation and strategic management. Company strategy will be different at different stages. For example, if the industry is expected to be in the embryonic period,

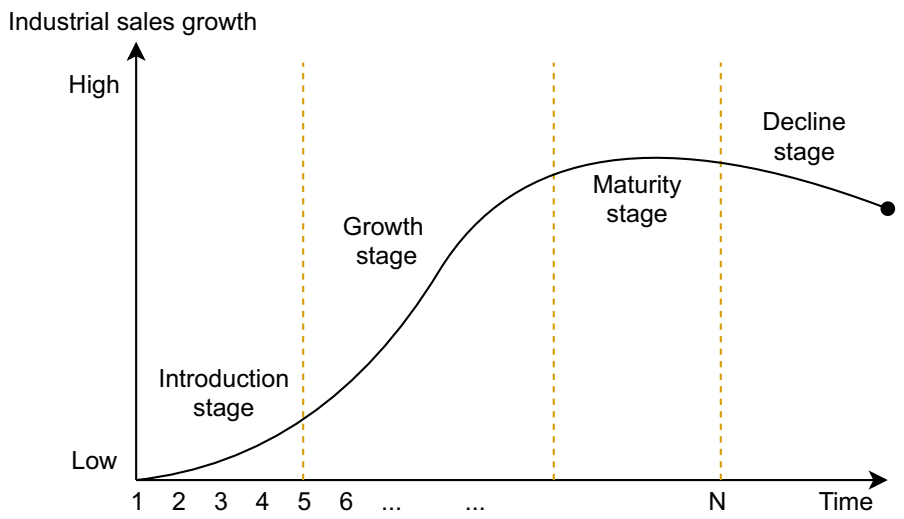

Fig. 8.2 Life circle of industry development 
you can forecast that the industry will have a good development potential in the future; the market demand will increase. Companies who have the industry technology can greatly enlarge capacity to provide more products to the market. Companies without independent technology need to manage to have the technology as soon as possible in order to enter the industry, and strive to keep up with the growth of the industry. In the early 1980s, China's auto industry was just in its infancy. In 1984, China's per capita disposable income was only $\$ 651$, and many companies were skeptical about whether China's future economy would have high-speed development, while the German Volkswagen made strategic decisions and stationed in the Chinese market. Volkswagen used the technology from the home country to launch the Santana sedan in the Chinese market, when the Chinese auto industry was in its embryonic period of development. The price of the car was expensive and Volkswagen entered a game that there was almost no competition, the product was expensive and the consumer knew little about the product in this industry at that time.

In the growth period, with the continuing growth of market demand, the number of manufacturers in the industry is gradually increasing, and the industry's production capacity has been rapidly improved, then the industry began to compete. Small and medium enterprises look for market segments to avoid direct competition with large enterprises in the industry. At the same time, companies in the industry need to continue to strengthen marketing efforts and improve product quality, or develop and launch new products to meet intensified competition.

In the maturity period, the industry demand declines. Small and medium-sized enterprises will consider whether to withdraw. Sales and revenue of capable enterprises in the industry will decline because of the low demand. Companies in the industry need to control and cut costs to ensure profits.

For different markets, there will be difference in term of industry life cycle. For example, the automotive industry in the developed countries is already in mature stage, but is in the early growth period for the Chinese market in the 1980s. Therefore, the resources and capabilities owned by a company which may have not been optimistic in a mature market may still be popular in other markets.

\section{(2) Consumers}

Consumer study is generally introduced in the "marketing" course in detail in business education programs. In terms of strategic decision-making, the understanding of consumers mainly includes the following issues: who are my consumers, or potential consumers (or to whom I provide products or services)? What are their motivations for buying my product? How large is this group? What is the future trend of this group? Will it continue to grow or fall?

"Who are my consumers": This question concerns about the segmentation of consumers in the industry. New comer of the industry has to answer this question. By answering this question, company will not only know the focus of its business (or know what industry you will compete in), but also clarify who will be my 
competitors in the market. For example, if you are a corn plastic producer, and if you only provide raw materials, then your business will be mainly in the field of raw materials. But if you make a variety of finished products such as quilts, clothing and even sanitary napkins out of the materials, you enter into a number of industries at the same time. Your businesses are not just in the corn plastic materials industry, you will compete with lots of major competitors in several industries.

Shifting of market position 1: For enterprises in the industry, sometimes they also need to re-examine the question of "who is my consumer". Suppose your original product positioning is high-end, but the industry's main market demand is in the low-end, you need to re-answer "are they my consumers" (To answer the question "Do I want go into this segment market" from a strategic point of view, or do I need a transfer of my strategic market positioning)? For example, in the early 1990s, Chinese people had lower incomes, low-price cars (120,000 RMB and below) were favored by the market, and some multinational auto manufacturers in China began to consider "whether they are my consumers". Finally GM and Volkswagen have specifically developed cars for this market segment.

Transfer of market position 2: The market may evolve into another direction. For example, with the development of China's economy, Chinese people's income continues to increase. In 90s, car price with more than 200,000 RMB is out of question for many families. While from 2010, the purchase of 200,000 RMB price of the cars is no longer a difficult thing for some families. Li Shufu saw the opportunity in the Chinese market. The consumers of Geely company cars mainly favored the low-cost cars before. After the acquisition of Volvo, the market's high-end groups have become auspicious target consumers.

Consumers transfer: Your consumers are not always your customers, and they will not love you forever as your parents. They will digress. Under situations that when there is a better product in the industry (same price with better quality), or there is a lower price of the product (with the same quality), decline or increase of income of consumers, or consumers have better knowledge of product, or even when the value of their life changes, consumers will leave you. Therefore, when your product is targeted at a specific group, you need to understand their income and their emotions of pleasure, anger, sorrow, and joy.

The market is composed of consumers. An industry in the market is like the tide of the sea, a wave after another. This wave embraces low-end market, that wave punches a high-end market. The causes of these waves are political and economic changes in the country or region, and changes of product technology in the industry, or business model changes. Consumers are rational, they will choose their own "value" of the product (or service) based on how much money they have in their own pockets.

Strategic decision-makers need to focus the market wave in the industry, the recent market and the future trend? What are the characteristics of future market demand? Where will the future market transfer (regional transfer, or different demands in the same region)? Assessment and confident of decision makers on these issues is critical to strategic decisions. 


\section{(3) Competitors}

In addition to know the competitor's strengths and weaknesses, it is necessary to understand the trend of quantitative change of competitors in the industry and where the industry leaders are developing (including new product development, business model, organization management and other changes), in case of any breakthrough development that will threat you.

For example, competitors introduce the product with better quality, better function than you. In the competition you are forced to cut price or even to be eliminated. Such as, the three giants in the mobile phone industry: Motorola, Nokia, Ericsson, were eliminated by the market because of the emergence of Apple, with the new smart phone.

Business model innovation usually brings greater value for consumers, such as better service, lower price (cost), faster response and so on. Innovation or change in the business model in the industry generally does not happen very often, but when it does, it often brings to the industry a subversive revolution. Such as the delivery company's door-to-door service, imposing a great threat to the traditional postal service; China's online car booking services and other new business models, have an impact to the traditional taxi; online Alipay has impact on traditional bank payment business. With government's good regulation and other financial arrangement, good $\mathrm{P} 2 \mathrm{P}$ financing may also intimidate traditional banking.

Company strategic decision-makers need to have a good understanding of the own organization, consumers, and the competitors. If the decision-makers know the company's resources and ability as clear as possible, understand the habits and emotions of consumers, know the key information of competitors, they know well of their own and the industry as opposed to amateurs if not. On the basis of full understanding of the company itself, industry, consumers, competitors, decision-makers can make better strategic decisions.

\section{References}

Amit, R., \& Schoemaker, P. (1993). Strategic assets and organizational rent. Strategic Management Journal, 14(1), 33-46.

Barney, J. B. (2001). Is the resource-based "view" a useful perspective for strategic management research? yes. Academy of Management. The Academy of Management Review, 26(1), 41-56.

Collins, H. M. (2010). Tacit and explicit knowledge. Chicago, IL: University of Chicago Press.

Hill, C., \& Jones, G. (2007). Strategic Management (In Chinese) (7th ed.). Beijing: China Marketing Press.

McCall, G. J., \& Simmons, J. L. (Eds.). (1978). Identities and interactions. An examination of human associations in everyday life. New York: Free Press.

Vernon, R. (1979). The product cycle hypothesis in a new international environment. Oxford Bulletin of Economics and Statistics, 41(4), 255-267.

Vernon, R., \& Wells, L. T. (1966). International trade and international investment in the product life cycle. Quarterly Journal of Economics, 81(2), 190-207. 
Open Access This chapter is licensed under the terms of the Creative Commons Attribution 4.0 International License (http://creativecommons.org/licenses/by/4.0/), which permits use, sharing, adaptation, distribution and reproduction in any medium or format, as long as you give appropriate credit to the original author(s) and the source, provide a link to the Creative Commons license and indicate if changes were made.

The images or other third party material in this chapter are included in the chapter's Creative Commons license, unless indicated otherwise in a credit line to the material. If material is not included in the chapter's Creative Commons license and your intended use is not permitted by statutory regulation or exceeds the permitted use, you will need to obtain permission directly from the copyright holder.

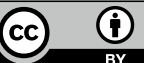

